\title{
Vitamin D Levels Affect Breast Cancer Survival Rates: A Reply
}

\author{
Curtis J. Wray, MD, MS
}

McGovern School of Medicine, University of Texas Health Sciences Center at Houston, Houston, TX

\section{TO THE EDITORS:}

I would like to thank Dr. Grant for his thought and letter to the editor in response to the recently published article. ${ }^{1}$ The information provided in his letter and the references are interesting and may provide significant insight into race-related breast cancer survival disparities. His cited reference 2 is an excellent resource, and I strongly suggest that all investigators with an interest in this topic read this important manuscript. These studies should encourage investigators to consider new or alternate hypotheses regarding the epidemiology and link between race and breast cancer.

\section{REFERENCES}

1. Wray CJ, Phatak UR, Robinson EK, et al. The effect of age on race-related breast cancer survival disparities. Ann. Surg. Oncol. 2013; 20:2541-47. 